\title{
VIAJEROS ESTADOUNIDENSES EN LA MANCHA
}

\author{
Domingo Fernández Maroto \\ Universidad Nacional de Educación a Distancia \\ Francisco Javier Sánchez-Verdejo Pérez \\ Universidad Nacional de Educación a Distancia
}

\section{RESUMEN}

A lo largo de la historia los escritos de viajes han resultado interesantes y sugerentes por la información que aportan, la referencia a lugares concretos y la forma de percibir la realidad en función de quien escribe, entre otros niveles. Los temas tratados suelen referirse a la vida social, las costumbres del lugar que se ha visitado, incluso se describen las ciudades, resaltando los aspectos más llamativos. Pero no olvidemos que los relatos tienden a responder a unas coordenadas sociales, culturales, económicas y políticas propias del momento histórico en que se escriben. En este artículo exponemos - acaso de manera sucinta- algunos ejemplos de escritos que viajeros estadounidenses han dejado acerca de La Mancha en general y de Valdepeñas en particular. Centraremos nuestro estudio fundamentalmente en el siglo XIX y primer tercio del siglo $\mathrm{xx}$, tratando relatos y comentarios variopintos sobre las gentes, la pobreza de los pueblos manchegos, las malas comunicaciones, y otros muchos aspectos que quedan reflejados en la retina del viajero, pasados luego por el cedazo de la observación crítica antes de ser plasmados en el papel.

Palabras Clave: libros de viajes, viajeros estadounidenses, La Mancha, Valdepeñas.

\section{NORTH AMERICAN TRAVELLERS IN LA MANCHA}

\section{Abstract}

Throughout history travel writings have been interesting and suggestive thanks to the information they provide, the reference to specific places, and the way of perceiving reality based on who has written them, among other considerations. The discussed topics usually refer to the social life and customs of the place that has been visited, and cities are described, highlighting their most striking aspects. However, we cannot forget that the writings tend to respond to certain social, cultural, economic and political demands of the historical moment in which they are written. In this paper we intend to briefly outline some examples of travel writings that American travellers have written about La Mancha in general and Valdepeñas in particular. We will focus our study on the nineteenth century and the first decades of the twentieth, dealing with stories and commentaries about people, the poverty of the people from La Mancha, bad communications, and many other aspects that are reflected in the retina of the traveller, then passed through the sieve of the critical observation before being expressed on paper.

KeYwords: travel books, American travellers, La Mancha, Valdepeñas.

DOI: http://doi.org/10.25145/j.refiull.2019.38.005

Revista de Filología, 38; enero 2019, pp. 79-93; ISSN: e-2530-8548 
La noción de viaje tiene una larga historia, así como el interés y la necesidad en reflejar el viaje en sí, es decir, las impresiones y las opiniones derivadas de la experiencia viajera. El viaje es inherente al género humano; el hombre se pone en marcha en busca de aquellas cosas o valores que habitualmente no se hallan a su alcance. Desde la Prehistoria se tiene constancia del peregrinar del hombre a la búsqueda de su sustento material o espiritual; no en vano, la escritura de literatura de viajes es una actividad que los hombres han disfrutado desde los tiempos de Gilgamesh (Smith 2001: ix). El sentido último del viaje puede tener múltiples facetas, pero en este caso nos interesan dos en especial: por un lado, la narración del viaje, y por otro las reflexiones que se realizan al hilo de dicho periplo.

La Península Ibérica ha sido desde la Antigüedad hasta nuestros días un destino bastante habitual de viajeros, y un buen número de aquellos nos ha dejado la narración de sus peripecias. En algunos momentos, las narraciones de los viajeros llegaron a tener un peso específico en la cultura del país de origen, y también en el nuestro. No en vano, en Espańa siempre nos interesó saber cómo nos ven los extranjeros (Campoy 1963). En efecto, pocos lugares cuentan con tantos visitantes y relatos de viaje como España. Washington Irving tal vez sea el más famoso, pero sin ser con mucho el único, de una larga lista de extranjeros -en este caso que nos ocupa norteamericanos- que legaron sus palabras y páginas como memoria de su paso por nuestro país. Como veremos en el presente trabajo, no solo debe hablarse de los hombres, pues si hasta hace poco tiempo se pensaba en ellos de manera automática, en esta lista faltaban los testimonios ofrecidos por mujeres.

La literatura de viajes es una interesantísima fuente de información, es la mirada del otro, que en muchos casos percibe y pone de relieve cosas que para el ciudadano no tienen el menor valor por formar parte de su acervo. También a veces, a través de esas miradas, se cambia la percepción de lo propio, iniciándose una suerte de encuentros y desencuentros sumamente interesantes. Los viajeros que analizaremos aquí realizan sus narraciones con intenciones muy diferentes: diarios, descripciones geográficas, cartas, relaciones diplomáticas e informes militares, relatos del viaje, artículos periodísticos, entre otros formatos, en los que recogen cuanto ven, desde lo cotidiano a lo maravilloso, mostrando en muchos casos la incomprensión por lo visto o lo vivido. La escritura de viajes es un género único, ecléctico, que ha servido, en palabras de William Stowe, de «meeting place for various narrative voices, literary styles, levels of speech, and kinds of subjects» (1991: 243). Una parte significativa de la escritura de viajes de los siglos XVIII y XIX no fue nunca publicada, aunque a menudo circulaba entre amigos, familiares; gracias a la labor de investigadores en escritura de viajes y expertos en temas de memoria histórica, entre otros, algunos de dichos textos poco a poco han ido saliendo a la luz, sorprendiendo a los lectores modernos con sus reveladoras descripciones de antaño.

Durante las últimas décadas, el estudio de los distintos tipos de viajes se ha convertido en uno de los principales objetivos de investigación de diversas disciplinas académicas. Estrechamente vinculados con el estudio de estos viajes se encuentran los trabajos sobre las teorías de la percepción del otro, la mirada a lo ajeno y otras materias similares que igualmente constituyen campos de investigación muy trabajados recientemente. En efecto, tanto los trazos negativos que dibujan la imagen de 
España como las ricas apreciaciones de su tradición y cultura conducen a plantearnos el funcionamiento de la noción de identidad en torno a tres elementos básicos. Primero, la identidad propiamente dicha; segundo, los procesos operativos de estas visiones; y, tercero, el modo en que los distintos actores sociales las comprenden, es decir, el modo en que se perciben los diferentes procesos de percepción. Una percepción que, al igual que los restantes elementos que configuran la identidad, adquiere un marcado carácter dialéctico y, por lo tanto, contradictorio, en ese contexto de relaciones entre el yo y los otros (Bruner \& Tagiuri 1954; Allport 1974; Yzerbyt \& Schadron 1996).

El presente trabajo intenta acercarse a la visión y análisis de la situación de España proporcionada por los viajeros estadounidenses. Su evaluación se vio influenciada por una serie de estereotipos relativos al mundo hispánico que están inmersos en la identidad nacional americana. Sin embargo, los intelectuales, periodistas y viajeros usaron estos prejuicios para llegar a conclusiones opuestas, es decir, no se daban las condiciones para que los viajeros estadounidenses se vieran libres del poso de imágenes comunes que lastraba su visión sobre nuestro país. En este sentido, remitimos al lector a la advertencia que hace el antiguo secretario de Estado Elihu Root en el primer número de Foreign Affairs (1922: 6), una revista fundada precisamente para satisfacer la creciente demanda de una mayor compresión de los asuntos internacionales.

El poso permanente de prejuicios y estereotipos en relación con España que conformaban la impresión de muchos estadounidenses tenía una doble procedencia. Gran parte de los mismos dimanaba de la colección de tópicos que componían la conocida como Leyenda $\mathrm{Negra}^{1}$, proveniente a su vez de la herencia cultural inglesa. No en vano, muchos se reforzaron y reelaboraron durante el siglo XIX, paralelamente a la construcción de la identidad nacional estadounidense. A este respecto, los Estados Unidos concibieron su propia excepcionalidad en contraposición a la situación que supuestamente existía en Europa. Dentro de este juego de espejos y reflejos negativos, Espańa ocupó un lugar prominente. En la mente de los estadounidenses, España representaba el polo opuesto a sus propias aspiraciones. Si los Estados Unidos se veían a sí mismos como fruto del protestantismo en sus formas más puritanas, España se presentaba como la víctima de la intolerancia propia del catolicismo. Esa diferencia religiosa se había manifestado en varios terrenos, separados, pero igualmente vitales. En el campo político, la flexibilidad protestante había permitido el surgimiento de formas representativas de organización, mientras que España se había visto condenada a sufrir toda una larga lista de gobiernos de corte absolutista o autoritario. En la esfera económica, la religión protestante había favorecido el surgimiento de la

${ }^{1}$ La supremacía llevada a cabo por los Habsburgo durante el siglo Xvi con respecto al resto de Europa les hizo granjearse una serie de críticas que en 1914 Julián Juderías agrupó bajo el término de Leyenda Negra. El contexto histórico de ese momento hizo que dichas críticas se relacionaran de manera directa con la religión, que acabó por aglomerar las protestas políticas, económicas y sociales. El auge de los nacionalismos acabó encaminando las críticas hacia lo español y su representación política del momento, Felipe II. 
iniciativa individual, fomentando el libre comercio y, por ende, la acumulación de riquezas. Sin embargo, el catolicismo había condenado el capitalismo, llevando a los espańoles a una dinámica de retraso con respecto a sus vecinos. Todo lo anterior situaba a España, dentro de la particular jerarquía estadounidense que aplicaba al resto de naciones, en un lugar inferior. El único aspecto positivo de esta visión de lo español residía en el atractivo folclórico de alguna de las tradiciones nacidas precisamente de esta cultura del atraso.

Resaltan, en efecto, las alusiones a la cara colorista y costumbrista del principal país de la Península Ibérica. El toreo constituía un tema clásico, que nunca se dejaba de vincular precisamente con el inherente anacronismo característico de todo lo español. Así lo hizo la conocida Time Magazine en una de las tres portadas que dedicó a España durante la década de 1920. En su número del 5 de enero de 1925, esta publicación se hizo eco del mito romántico de la Espańa castiza, reproduciendo en su cubierta una fotografía del torero Juan Belmonte. La imagen iba acompañada de un artículo en páginas interiores, encabezado por el título «Toreador», que indudablemente remitía a la famosa canción del torero incluida en la ópera Carmen de Georges Bizet. Allí se hacía una glosa de la enorme expectación que el espectáculo taurino despertaba en la sociedad espańola; fervor que era explicado por el carácter pasional y en cierta medida primigenio de los habitantes de España.

A la vista de lo anterior, no nos extraña, pues, que muchos de los norteamericanos que venían a nuestro país lo hacían cargados de tópicos en torno al carácter de los españoles.

Aunque durante unas décadas España, y en concreto La Mancha, quedó al margen de esos circuitos, pues se consideraba que no había nada de interés que estimulase la formación y enriqueciese los conocimientos de esos viajeros ilustrados, llega un momento en el que se produce un viraje en las preocupaciones de los viajeros extranjeros en general y los norteamericanos en particular, que empiezan a incluir la tierra del Quijote como una o varias etapas de sus periplos. A mediados del siglo xviII se constata que los continuos y constantes viajes a los mismos lugares, las entrevistas con las mismas personas y la impresión de libros de viajes en los que se describían los mismos lugares geográficos llegaron a causar tedio, que no aburrimiento, entre aquellos que tenían que repetir una y otra vez lo que otros ya recorrieron, vieron y contaron. De modo que para esa época quienes se organizan para recorrer España empiezan a buscar otros lugares que descubrir para poder contar nuevas experiencias. Por tal razón se va trasladando la ruta de esos viajeros hacia la Europa meridional, y en concreto hacia el centro-sur de la Península Ibérica, que empieza a ejercer atracción entre los viajeros provenientes de Norteamérica por sus pretendidos caracteres exóticos, al ser considerada una tierra dominada por la mentalidad y las costumbres católicas.

Afirma Félix Pillet que «entre Madrid y Andalucía solamente Toledo tenía interés para la mayor parte de los viajeros. Los que recorrían nuestra actual región la atravesaban de paso, excepto aquellos pocos que tuvieron interés por seguir el camino de Don Quijote» (2006: 41). La lectura de la historia de Don Quijote conllevó la idealización de las tierras donde sucedían sus aventuras, al mismo tiempo que una lectura realista movió a los espíritus sensibles del XIX a intentar revivir las andanzas 
de Don Quijote trasladándose a los propios escenarios donde estas discurrían. Por tanto, a la vista de lo anterior, podemos afirmar que la región castellano-manchega se convertirá en una de las más interesantes para la mayoría de los viajeros por su atractivo paisajístico y patrimonial, aparte de por su cercanía a la capital de España y la facilidad de las comunicaciones. Los visitantes dan buena cuenta de la herencia histórica de Toledo, las imágenes del paisaje manchego, los personajes quijotescos y la gastronomía cervantina.

Teniendo en cuenta la afirmación del historiador literario William Charvat en el sentido de que durante gran parte del siglo xIx el libro de viajes fue el segundo género más leído en los Estados Unidos después de la historia (1959: 74), no es extraño que los escritos de viajes adquiriesen una posición relevante, dado que arrojaban luz sobre todo lo foráneo en general y lo español en particular. La historia del viaje está íntimamente unida a la escritura y, así como la forma y la motivación de los viajes cambian, consecuentemente también lo hace el relato que sobre ellos se construye. No en vano, ya hacia el siglo XVIII, un momento histórico marcado profundamente por la razón y la ciencia, la literatura de viajes implicaba hipótesis verificadas posteriormente por lo que el viajero atestiguaba. Tal como observa el eminente crítico y lexicógrafo Samuel Johnson en una de sus cartas, «the use of travelling is to regulate imagination by reality, and instead of thinking how things may be, to see them as they are» (1892 I: 254). Es decir, el discurso de la razón aplicado a la observación ligada a la literatura de viajes.

Los siglos XVIII y XIX son testigos de una gran afluencia de viajeros de habla inglesa a nuestro país. Sin embargo, un siglo de diferencia supone un cambio notable desde el punto de vista de la literatura que estos viajeros producen. Sus escritos nos plasman la realidad de dos épocas con concepciones del mundo bastante divergentes, como son la Ilustración y el Romanticismo. Los viajeros estadounidenses que recorrieron Espańa en el siglo XIX conformaban indudablemente un grupo heterogéneo (Buzard 1993: 160; Stowe 1994: 18-25) que se veía atraído por el estudio de la otredad (Gifra 1998: 62). El descubrimiento de Europa llevado a cabo por estos viajeros se puede dividir en varios períodos. A las décadas iniciales pertenecen los escritos de aristócratas, profesores y diplomáticos que aún seguían la filosofía dieciochesca del tan conocido y exclusivo Grand Tour o Le Grand voyage, aunque añadiendo la influencia de una clara sensibilidad romántica. Los caballeros que podían permitirse realizar este periplo solían ser norteamericanos blancos y adinerados que se codeaban con los miembros de su misma clase en Espańa. Más tarde, este itinerario reservado a una minoría dejó de ser exclusivo de la aristocracia para, en palabras de John Brewer, pasar la esfera de la «less socially elevated and less well-educated people», incluyendo las mujeres (citado en Buzard 2002: 42). Será entonces cuando encontramos corresponsales, fotógrafos, cineastas, escritores, artistas, políticos y periodistas, todos ellos reunidos bajo el genérico nombre de viajeros. Esta nueva era se convertiría entonces en lo que Paul Fussell ha denominado como "heyday of travel and travel writing» (1987: 271), esto es, una época en que un número mayor de viajeros de orígenes diversos empezaría a desplazarse con diferentes propósitos y como consecuencia de ello se irían publicando más textos. Buen ejemplo de los cambios experimentados por el viaje y la escritura en tanto que prácticas culturales relevantes del momento, 
consideramos pertinente traer a colación los siguientes datos: entre los años 1800 y 1850, se publicaron 325 libros de viajes, pero entre 1850 y 1900 ese número aumentó sorprendentemente a 1440 (Schriber 1995: xxiv).

Para los estadounidenses, la tradición del «European tour» servía a modo de viaje iniciático y de aprendizaje ${ }^{2}$. En consonancia con esta tradición el viaje se considera como una «opportunity to achieve notable distinction through self-defining experience far from home» (Smith 2001: ix). La apertura progresiva del viaje fue lenta en esencia, viéndose drásticamente afectada por las guerras napoleónicas, la Guerra Civil Americana y, ya en el siglo xx, por las dos guerras mundiales. Espańa, a partir del inicio de su lenta decadencia como Imperio, había quedado en una posición periférica dentro de las rutas de viajes culturales. En el siglo xvin el Grand Tour se dirige principalmente a Italia, pero paradójicamente será un acontecimiento negativo, la invasión napoleónica, el que modificará el escenario europeo y hará que, tras la Guerra de la Independencia, España vuelva a ser objeto de curiosidad. Esta es la generación de Washington Irving y otros escritores que abrieron las puertas a la participación norteamericana en la construcción del mito de la España Romántica. Estos autores escribieron narraciones sobre viajes indudablemente interesantes, puesto que retrataron y mostraron un país que carecía de modernidad.

Pese a que es el espíritu ilustrado el que impera en todos los escritos producidos a raíz de los mencionados tipos de viajes, estos solían ser de tan poca duración y las relaciones de los viajeros se solían constreñir tanto a aquellos que compartían su misma nacionalidad o lengua que, aunque pretendieran lo contrario, suelen caer en imágenes nacionales estereotipadas y tópicos que darán lugar en el siguiente siglo a la imagen de España como país romántico por excelencia frente al resto de Europa. Durante el siglo xIx las circunstancias generales van a cambiar produciendo un fuerte incremento de viajeros a la Península y configurando una importante literatura de viajes sobre nuestro país. Las causas de este auge son varias: desde el punto de vista político o bélico, es una época de enfrentamientos. Al mismo tiempo, sucesos como la Guerra de la Independencia, las Cortes de Cádiz o las Guerras Carlistas hacen correr por el resto de Europa noticias sobre España. Paralelamente, nos encontramos con el triunfo de la corriente romántica en Europa que supone para España el resurgir de unos valores antes olvidados, como son la literatura del Siglo de Oro o la huella de la cultura musulmana en la arquitectura árabe; el arte español se descubre en gran medida debido a los saqueos por parte de los invasores franceses (Fernández e Ivanova 2013: 58-62).

En Europa comienza a hacerse cierto tipo de turismo, en donde la imagen acuñada de España ya en el siglo anterior como lugar salvaje, exótico y atrasado atrae cada vez más al viajero en busca de esa imagen tópica donde se ensalzan las -para

${ }^{2}$ La idea de aprendizaje a través del viaje se remonta a John Locke y su Ensayo sobre el entendimiento humano (1690), donde el filósofo afirma que el conocimiento se adquiere de forma empírica, por lo que el viaje suponía una exposición a estímulos que el turista asimilaba en un proceso de aprendizaje, asegurado por un guía o tutor que supervisaba los avances realizados (Bautista 2010: 40). 
ellos-cualidades raciales hispánicas y donde todos los españoles parecen ser toreros, gitanos, contrabandistas o bandoleros, y todas las mujeres esconden bajo su mirada a la tan buscada y deseada Carmen ${ }^{3}$. Esta visión distorsionada hasta la caricatura se debe en parte al desconocimiento de la realidad, del terreno y del idioma, ante lo que llegan con prejuicios establecidos de antemano, bien procedentes de aquellos que les han precedido en su periplo, o extraídos de los arquetipos recobrados de la literatura española. Muchos de los viajeros buscan experimentar los estimulantes placeres de lo arcaico, lo desconocido, lo fantástico pero deseable al mismo tiempo (Ferrús 2011) en la seguridad de que se volverá al orden natural al volver al país de origen. Si a todo ello unimos el fuerte contraste climático entre su país de origen y el nuestro, no nos equivocamos si afirmamos que en el fondo les gusta el tópico España es diferente. Es posible entender que esas ideas arraigaran de tal manera en el concepto del país y que incluso hayan llegado hasta hoy en día y sigan conformando para muchos la imagen de lo español.

La mejora en las comunicaciones y la bonanza económica llevaron a los viajeros norteamericanos de las últimas décadas del siglo XIX a recuperar el interés por el Viejo Mundo en general y España en particular. Por tanto, la Península Ibérica se convirtió en uno de sus destinos favoritos. Este es el tiempo del turista, en la acepción moderna de la palabra, encarnado en los personajes que Mark Twain creó para su conocido libro de viajes The Innocents Abroad (1869). Los viajeros (hombres y mujeres) que conformaron las multitudes del viaje europeo de finales del siglo XIX también escribieron literatura de viajes. Se sintieron inspirados y deslumbrados por conceptos como el de la esencia de España (desconocido y malentendido a partes iguales) y especialmente por el de la Andalucía morisca, siendo la tierra de Don Quijote consecuentemente una zona atrayente, a pesar de la ausencia de comodidades y las altas probabilidades de sufrir robos. La imagen idealizada que había construido el mito de la Espańa Romántica durante la primera mitad del siglo xIx era tan fuerte que permaneció en la imaginación estadounidense durante muchas décadas. Los viajeros norteamericanos, influenciados como estaban por las visiones orientales y medievales de la Península Ibérica diseminadas tanto por autores europeos como por algunos de sus compatriotas, esperaban encontrar un país lleno de sensualidad, asociaciones históricas, aventuras y leyendas. En suma, un viaje al pasado.

En el siglo xix España empezará a ser muy visitada. Desde principios de siglo nos encontramos con un elevado número de libros de viaje sobre nuestro país. La razón principal de este aumento es el gran número de viajeros extranjeros que estuvieron en España, aunque no exclusivamente, durante la Guerra de la Independencia. Los acontecimientos desarrollados en relación con el enfrentamiento bélico se divulgaron y magnificaron en la época romántica. Durante esta época se consideró Espańa un destino natural. Así se podía entrar en contacto con lo indómito e incivilizado, junto al evidente y exótico encanto del mundo musulmán. El tema

${ }^{3}$ Para más información sobre los factores que produjeron este inusitado incremento en los viajeros y la literatura de viajes en el siglo XIX, véase Bernal Rodríguez (1985) y López Ontiveros (1988). 
del viaje a España es recurrente en la literatura del siglo XIX, sobre todo a partir de que los gustos románticos de los viajeros -casi todos hombres en las primeras décadas- hicieran que se hablara de España como el país más romántico y peculiar de Europa. El viajero romántico «esperaba encontrar en Espańa un universo radicalmente opuesto al de la realidad diaria de su país de origen, donde lo cotidiano sorprendiera y pudiera hallarse lo primitivo, la magia de lo árabe, la sobriedad de lo medieval cristiano y la leyenda de las catedrales góticas» (Ortas 2005: 60). Es, en definitiva, una literatura que se caracteriza por presentar sobre todo las impresiones de los viajeros decimonónicos y deja de lado las prolijas descripciones y análisis de los viajeros ilustrados.

Llegados a este punto, nuestro interés pasa por centrarnos a continuación en la experiencia de viajeros que realizaron el periplo entre Estados Unidos y España durante el siglo XIX, incidiendo en los aspectos más llamativos de su paso por La Mancha. Sus testimonios son una fuente documental coetánea para la construcción del crisol social español del momento. Sus relatos son los de unos viajeros que, con el distanciamiento necesario que proporcionan los ojos de un extranjero, ofrecen una visión generalizada de lo narrado. Nos han legado obras que presentan información relevante acerca de la vida cotidiana tanto del viajero como de los españoles, de los placeres, de las incomodidades y otros elementos que llaman su atención en esta especie de peregrinación romántica: los toros, los colores, el romancero, los bandidos, los mendigos, el arte... Muchos de estos autores aludirán también a la logística del viaje, a los caminos, las diligencias y las horrendas posadas, la confusión y el desorden, la indolencia del pueblo y la inutilidad o corrupción de los funcionarios. No se puede obviar el papel que estos textos han desarrollado a la hora de diseminar una visión idealista o sesgada de España. Así, se analizará por qué esta visión ha tenido tal influencia y a menudo aparece conectada íntimamente a ciertas ubicaciones y acontecimientos históricos. Como podremos ver en los ejemplos aportados, un gran número de los viajes a España en el siglo XIX no fue solamente inspirado por el Romanticismo o los deseos de aventuras personales, sino también por el interés de explorar científicamente un país poco conocido. De ello resulta la necesidad de que las publicaciones fruto de dichos viajes deban ser investigadas asimismo bajo múltiples enfoques interdisciplinarios, aspecto este que dejamos para futuros proyectos.

Los prejuicios de algunos viajeros del siglo xix son comparables a los de la media del turista moderno. De igual modo que en la actualidad los turoperadores y otros medios de comunicación alimentan a los turistas postmodernos con múltiples imágenes del exterior, así los libros de ficción, los relatos de viajes y la literatura periódica influyeron en los viajeros del siglo xix. Irving, como muchos de sus contemporáneos, había leído algunos clásicos españoles antes de residir y viajar por nuestro país entre 1826 y 1829. Cabe tener en cuenta que estas narraciones de viajes iban destinadas a un público lector que se estaba expandiendo y gracias a su educación se había vuelto más exigente; una audiencia mayor significaba mayor variedad de lectores con diferentes necesidades. Esta multiplicidad de lectores y lecturas explica la pasión con la que escribe otro viajero norteamericano también influido por la literatura espańola. Se trata del neoyorkino Alexander Slidell Mackenzie, autor de A Year in Spain (1829), un libro que se aleja de las fantasías del coetáneo Irving 
para mostrar un país desgarrado y peligroso. Consecuentemente, un viaje a Espańa no significaba para un viajero norteamericano -al menos exclusivamente- una oportunidad para ampliar sus horizontes, sino también una forma de confirmar sus ideas adquiridas previamente acerca de una cultura extranjera. La escritura de un libro de viajes suponía un ejercicio retórico que concluía ese proceso creando a su vez nuevos viajeros.

Autores aclamados por la crítica no fueron ajenos a la llamada de la escritura de viajes. Algunos británicos y estadounidenses que cultivaron el género y hoy forman parte del canon literario son Washington Irving, Henry W. Longfellow, Ernest Hemingway, George Orwell, Evelyn Waugh, Edith Wharton y Gerald Brenan. Entre los viajeros que marcaron su impronta en la imagen de España cabe destacar a Richard Ford por su Handbook for Travellers in Spain and Readers at Home (1845) y a Washington Irving por sus popularísimos Cuentos de la Alhambra (1832). El primero, precursor de los hispanistas, se adentrará en descripciones y análisis del país, de sus instituciones, costumbres y clases sociales. No es, en este sentido, un romántico sino casi un sociólogo realista, que redacta un completísimo informe diplomático. Irving, historiador, se dejará llevar por la imaginación, pero recogiendo también leyendas y descripciones olvidadas. No en vano, quizás fuera Washington Irving el que mejor plasmara literariamente los paisajes naturales y humanos de la tierra manchega. Se lanzó a describir las sensaciones que le causaron las eternas estepas de la tierra que otrora recorrieran Don Quijote y Sancho Panza, incidiendo tanto en lo referente al paisaje como en las gentes que lo habitaron y recorrieron, incansables, de un lado a otro. Las inmensas llanuras de La Mancha, que se extienden hasta donde el ojo alcanza, atraerán el interés de Irving precisamente por su propia desnudez e inmensidad, llegando a compararlas con la grandeza del océano. Llegará a afirmar que la tierra, sus costumbres y la apariencia de sus habitantes tienen algo del carácter árabe.

Junto a la figura de Irving cabe también destacar a otros escritores menores aunque ciertamente interesantes pese a sus limitaciones literarias. En primer lugar, tanto por su status como por su obra, hay que mencionar al embajador y senador de Nueva York Samuel Sullivan Cox, autor de Search for Winter Sunbeams in the Riviera, Corsica, Algiers, and Spain (1870). La ruta de Cox por España es eminentemente costera (Valencia, Alicante, Elche, Murcia, Cartagena, Granada y Málaga), pero no por ello excluye una posible ruta interior que pasaría por Sevilla, Córdoba, Madrid y alrededores, Zaragoza y La Mancha, en concreto Toledo. El escritor judeonorteamericano Waldo Frank también recorrió La Mancha, la tierra del Quijote. Fue comentarista social sobre temas hispanoamericanos y españoles que plasmó en el libro Virgin Spain: Scenes from the Spiritual Drama of Great People (1926), reeditado en numerosas ocasiones. Nos encontramos con una visión de España y lo español muy diferente de la que hizo Washington Irving casi un siglo antes. Waldo Frank va llevando al lector norteamericano de la mano por la historia cultural, la sociedad y las costumbres de España en general y Castilla-La Mancha en particular. El libro, entre varios planos, muestra la cultura y la historia a través de figuras como el Greco o diversiones como las corridas de toros, dos elementos prototípicamente españoles identificados también con La Mancha. No en vano, debemos tener presente que los viajeros referidos en el presente artículo recorrieron, en su mayoría, las provincias del 
sur de España, prestando atención a las tres grandes ciudades de Sevilla, Córdoba y Granada. Este interés posibilitó que muchos de ellos recorrieran La Mancha, al ser considerada tierra de paso, y se quedaran impresionados por los encantos que desconocían de la tierra del Quijote, más allá del mítico personaje. Todo ello demuestra, una vez más, las ideas preconcebidas con las que iniciaban su periplo por La Mancha en general y, más concretamente, la zona de Valdepeñas.

Otro viajero estadounidense que transitó por La Mancha fue el empresario ferroviario y general del ejército unionista Charles Russell Lowell. Su hermano, el diplomático y literato James Russell Lowell, perteneciente al movimiento de los llamados Fireside Poets, también recalaría en nuestro país al ser nombrado embajador de los Estados Unidos en 1877. En relación con el tema que nos ocupa, sabemos que Charles Russell Lowell pasó por La Mancha y se quedó prendado del vino de Valdepeńas, tal y como lo expresa en una carta fechada el 16 de junio de 1856 que le escribió a su madre. En ella comenta que unos compañeros suyos tuvieron una mala experiencia viajando, pero «a bottle of Valdepenas, Don Quixote's favourite wine, made them forget» (Emerson 2005: 109). También fascinado por la historia de El lngenioso hidalgo don Quijote de La Mancha encontramos a August Florian Jaccaci, editor, pintor e historiador del arte que se propuso conocer los escenarios cervantinos y también las costumbres y el carácter de los manchegos. Su intención era recuperar o reencontrar el encanto de lo que Cervantes supo narrar y plasmar en su obra con maestría, gracia y humor. Jaccaci, que llega a La Mancha en 1894, sabrá diferenciarse de otros viajeros románticos, ofreciendo una visión personal de las gentes, los paisajes y las costumbres manchegas. Se guiará por su personal interpretación de la mítica historia narrada por Cervantes, interpretación que va unida a su propio bagaje cultural y a su visión estereotipada de las tierras y las gentes. En 1897 publica On the Trail of Don Quixote: Being a Record of Rambles in the Ancient Province of La Mancha. Esta obra es una apasionante sucesión de paseos por La Mancha que vio la luz con unos bellos dibujos del ilustrador español Daniel Urrabieta Vierge, con quien Jaccaci compartía amistad. El sexto capítulo, dedicado a la zona de Valdepeñas, inicia así la descripción de los alrededores de esta ciudad manchega: «En las primeras horas, el paisaje era sólo una llanura sin límites, bien amiga nuestra, por cierto; después fueron de vez en cuando apareciendo algunos vińedos, $y$, por último, la planicie era toda una inmensa viña perdida en el horizonte por los cuatro costados» (1915: 156). Acto seguido, Jaccaci presenta al lector la visión de Valdepeñas:

La próspera ciudad de Valdepeñas apareció en nuestro camino. A pesar de su gran importancia industrial, tenía todas las características de los humildes pueblos manchegos: una iglesia muy grande, y a su alrededor, dispersas, casas con negros tejados y paredes blancas. En las afueras estaban las bodegas, grandes casas en cuyas paredes, enjalbegadas, resaltaban unas letras negras de una vara de altura. Deploré esta incongruencia, motivada por el anuncio moderno, escandaloso, en un sitio tan primitivo, lleno de un dulce ambiente del pasado (Jaccaci 1915: 157).

El interés por lo quijotesco, por los vinos y por las gentes que se patentiza en los textos de los viajeros aquí comentados no puede, con todo, abarcar la mirada estadounidense sobre La Mancha sin contar con las diversas voces femeninas que 
también aportaron sus comentarios sobre esta región. Una de ellas es Merrydelle Hoyt, autora de Mediterranean Idylls. As Told by the Bells (1914). Su libro consiste en la original narración de una campana que cuenta su viaje en un automóvil por España en general y por La Mancha en particular ${ }^{4}$. Igualmente, sabemos que Ellen Louise Chandler Moulton, una conocida poeta y crítica norteamericana que gozaba de fama gracias a sus salones literarios en Boston y Londres, llegó a España en 1896, cuando contaba 61 años. Pasó en el país siete semanas y estuvo por La Mancha en su viaje desde Madrid a Córdoba. El primer capítulo de su obra Lazy Tours in Spain and Elsewhere (1896) constituye un interesante recuento de la vida de los españoles a finales del siglo XIX, ya que en él la autora cuestiona muchos de los tópicos que habían circulado acerca de España en general y La Mancha en particular: región famosa por las corridas y los encierros, tierra calurosa pero también llena de holgazanes, área peligrosa por los temibles pero atrayentes bandoleros, etc. Así, los estereotipos de violencia, vagancia o crueldad de los españoles, heredados de la Leyenda Negra diseminada por los anglosajones, son puestos en entredicho y contestados uno a uno. No obstante, la autora refiere que no existieron riesgos ni avatares reseñables, solo las dificultades propias de un terreno diferente, y hasta se lamenta de que no la hayan asaltado un grupo de forajidos para poder fabricar una buena historia que dejara huella en sus lectores. Durante su estancia, en cualquier caso, Moulton no encontrará rastro alguno de dicha leyenda ni gentes de corte inquisitorial, sino todo lo contrario. Además de desmentir esos estereotipos se encarga de recordar la necesidad de percibir y describir la realidad desde muchos puntos de vista, incidiendo en la importancia de intentar entender al otro, invitando al lector a enfrentarse a la realidad despojándose de los estereotipos. Es decir, abre un espacio dentro de las geografías románticas alternativas, calificando su estancia como una de las experiencias más placenteras de su vida. Cuando le llega la hora de partir se despide llorando.

Susan Hale es otra de las muchas escritoras viajeras norteamericanas que durante el siglo XIX visitaron España. En concreto, viajó a nuestro país en 1882, pero su obra, como la de tantas otras, no es conocida debido fundamentalmente a la falta de traducciones, aunque en los últimos años investigadores como Elena Carrera (2006) y Alberto Egea (2009), entre otros, han contribuido al reconocimiento de estas mujeres que fueron física y espiritualmente más allá de lo que estipulaban los rígidos límites de la sociedad victoriana. Hale, escritora, pintora de acuarelas, profesora y conferenciante, contribuyó con sus escritos y su estilo de vida a la emancipación femenina, abriendo el camino a otras mujeres en campos hasta entonces vedados para ellas. Hale describe la realidad de Espańa, incluida la castellano-manchega, incidiendo en tópicos como la impuntualidad de los trenes, o las descripciones románticas de los paisajes, dejando a España en general y a La Mancha en particular

${ }^{4}$ No fue este el único ingenioso recurso usado por la norteamericana. Así, se aprovechó de otros objetos como una almohada o una botella. La fecha de su publicación y el tema tan próximo a nosotros delata una nueva sensibilidad, de ahí que sus narraciones se envuelven con el brillo de lo animado, de lo fantástico en términos cercanos a lo que en unos años después eclosionará en el cine de Disney (Zabalgoitia 2015). 
en esa especie de limbo de eterno pasado, de inmovilismo, frente al progreso y al futuro que representaban otros países. Su obra es, en definitiva, bastante crítica con la realidad española y manchega.

La obra de Susan Hale y la de las otras escritoras viajeras tratadas aquí reflejan ese deseo de hacer algo diferente y de cambiar la situación de las mujeres. Para ellas, esta popularización del viaje y de su literatura fue especialmente importante porque les permitió salir física o metafóricamente de la esfera privada a la que la estricta sociedad victoriana las confinaba. Las escritoras de esa época encontraron además una forma de escapar de los géneros literarios aceptados como femeninos (novela sentimental y cartas, básicamente) al poder expresar su conocimiento científico, etnográfico, histórico, artístico o cultural a través de los libros de viajes, ya que estos eran considerados un "género menor" apto para las mujeres. Se convirtieron así en prolíficas escritoras con gran calidad literaria, y algunas tuvieron un cierto éxito de lectura en su época. Sin embargo, sus obras no han sido ampliamente estudiadas desde el ámbito académico ni, como mencionamos antes, traducidas, por lo que son desconocidas para el público de hoy.

\section{CONCLUSIONES}

Lo dicho en este breve trabajo nos lleva más allá de la polémica idealismorealismo para introducirnos en una cuestión que planteamos aquí como futura línea de investigación, a saber: el papel de la ideología. Estereotipos e ideología son dos cosas distintas, pero en gran medida relacionadas. La segunda puede definirse como un conjunto reducido de premisas, enraizadas en la propia herencia cultural, que sirven a un determinado grupo para dar sentido a sus propias acciones. De manera general, mientras esa comunidad se define a sí misma, marca cada vez más sus diferencias con respecto a otras sociedades. Y estas son contempladas generalmente a través de una serie de prejuicios o lugares comunes que permiten caracterizarlas de manera rápida y sucinta, aunque en ningún modo precisa. Así pues, a la par que los líderes de una colectividad perfilan su propia identidad, perpetúan una determinada percepción del resto de comunidades. Algo así ocurrió dentro de los Estados Unidos en relación con España. A medida que se conformaba una determinada visión de Norteamérica, se fueron acunando una serie de características que servían para describir a los pueblos europeos en general y a España en particular. Y al mismo tiempo que los elementos más sobresalientes de esa autoimagen estadounidense se consolidaban y adquirían durabilidad en el tiempo, también lo hacían los estereotipos referentes a Espańa y La Mancha. Con todo, ¿cuáles eran los elementos particulares de esa filosofía norteamericana y su relación con la visión de España?

Conviene recordar que muchos de los escritores tienen una gran biblioteca de viajes y cuando vienen a España suelen haber leído numerosos relatos de viaje de sus antecesores, no dudando en ocasiones en citarlos a lo largo de sus relatos. Los escritores visitan, pues, España con unos prejuicios, ideas preconcebidas y supuestos que a veces difícilmente les permiten observar disfrutando y aceptando lo que ven, de modo que en ocasiones sus relatos ofrecen algunas de las visiones más negativas 
de España. Por tanto, se mezcla el entusiasmo romántico con una marcada y progresiva decepción. A pesar de ofrecernos a veces una visión muy crítica y negativa del país, si obviamos ciertos prejuicios y comentarios peyorativos provenientes de sus sentimientos de pseudosuperioridad hacia un país que no consideran tan civilizado como el suyo, podemos considerar los relatos como un testimonio documental más de la España y de La Mancha del momento. No falto de errores, pero también lleno de verdades, datos, ideas o realidades de las que no tendríamos constancia si no fuese gracias a estos testimonios escritos.

¿Cómo puede esta otra visión ayudar a romper los estereotipos de los escritores sobre España? Reconocer a los autores aquí citados, así como a tantos otros que aún quedan por estudiar, y subrayar su aportación a la literatura de viajes, es un trabajo en curso. Creemos que los viajeros estuvieron mucho más involucrados de lo que se pensaba hasta ahora en la configuración del imaginario identitario en torno a España; los análisis aquí presentados son una visión diferente -la de los viajeros- sobre una realidad de las diversas regiones espańolas que siempre se ha considerado «otra» por el estereotipo del «Spain is different». En cierta medida se trata de una visión de La Mancha y de Espańa que no es tan diferente, y de unos viajeros extranjeros que consiguieron crear diversas geografías a través de sus visiones alternativas. Desde la perspectiva presentada aquí, estos viajeros visitaron La Mancha buscando los tipos y ambientes quijotescos al considerar que esta región había sobrevivido al paso del tiempo y conservaba intacta su esencia cervantina. Su búsqueda respondía, por lo tanto, a una determinada idealización del significado que atribuían a la figura ejemplar de Don Quijote y al objetivo perseguido por Cervantes. Sin embargo, encontraron otras peculiaridades de este entorno manchego, sobre todo cuando viajaban de paso por la comarca vitivinícola de Valdepeñas, generalmente hacia Andalucía. El vino de Valdepeñas y la fama que le antecedía provocaron más de un comentario entre los viajeros que, puestos a hospedarse o a degustar las viandas necesarias para seguir el camino, prefirieron hacerlo al calor de un vino de Valdepeńas. 


\section{BIBLIOGRAFÍA}

Allport, Floyd H. (1974): El problema de la percepción, Buenos Aires: Nueva Visión.

Bautista Naranjo, Esther (2010): Un americano en La Mancha. Tras las huellas de don Quijote, Ciudad Real: Centro de Estudios de Castilla-La Mancha (UCLM).

Bernal Rodríguez, Manuel (1985): La Andalucía de los libros de viajes del siglo XIX (Antología), Sevilla: Biblioteca de la Cultura Andaluza.

Bruner, Jerome \& Renato Tagiuri (1954): «The Perception of People», en Gardner Lindzey (ed.), Handbook of Social Psychology, Reading, MA: Addison-Wesley, 634-654.

Buzard, James (1993): The Beaten Track: European Tourism, Literature, and the Ways to "Culture", New York: Oxford University Press.

Buzard, James (2002): «The Grand Tour and After (1660-1840)», en Peter Hulme and Tim Youngs (eds.), The Cambridge Companion to Travel Writing, Cambridge: Cambridge Universtiy Press.

Campoy, Antonio M. (1963): Viaje por España. Cómo nos ven los extranjeros, Madrid: Biblioteca Nueva.

Carrera Marcen, Elena (2006): «Viajeras inglesas en la España del siglo xix: lugares comunes y visiones particulares», en Manuel Lucena Giraldo y Juan Pimentel (eds.), Diez estudios sobre literatura de viajes, Madrid: CSIC.

Charvat, William (1959): Literary Publishing in America: 1790-1850, Philadelphia: University of Pennsylvania Press.

Cox, Samuel Sullivan (1870): Search for Winter Sunbeams in the Riviera, Corsica, Algiers, and Spain, New York: Appleton.

Emerson, Edward Waldo (2005) [1907]: Life and Letters of Charles Russell Lowell, Columbia, SC: University of South Carolina Press.

Egea Fernández-Montesinos, Alberto (coord.) (2009): Viajeras anglosajonas en España. Una antología, Sevilla: Centro de Estudios Andaluces.

Fernández Maroto, Domingo y Tonka Ivanova Angelova (2013): «El Arte como botín de guerra. La Guerra Civil española y el expolio nazi», Universidad Abierta 30: 47-120.

Ferrús, Beatriz (2011): Mujer y literatura de viajes en el siglo XIX: entre España y las Américas, Valencia: Biblioteca Javier Coy d'Estudis Nord-Americans; Publicacions Universitat de València.

Frank, Waldo (1926): Virgin Spain: Scenes from the Spiritual Drama of a Great People, New York: Boni \& Liveright.

Fussell, Paul (ed.) (1987): The Norton Book of Travel, New York: W.W. Norton.

Gifra, Pere (1998): "Nineteenth-Century American Travel Writings on the Catalan-Speaking Community", Catalan Review 12 (1): 61-72.

Hale, Susan (1883): A Family Flight through Spain, Boston: Lothrop Publishing Company.

Ноут, Merrydelle (1914): Mediterranean Idylls, Londres: Duckworth.

IRving, Washington (1979): Letters: Volume II, 1823-1838, Ralph M. Aderman et al. (eds.), Boston: Twayne.

JACCACI, August Floriano (1897): On the Trail of Don Quixote, New York: Charles Scribner's Sons.

JaCCACI, August (1915) [1897]: El camino de Don Quijote (Por tierras de La Mancha), Ramón Jaén (trad.), Madrid: La Lectura. 
Johnson, Samuel (1892): Letters of Samuel Johnson, 2 vols., New York: Harper \& Brothers.

López Ontiveros, Antonio (1988): «El paisaje de Andalucía a través de los viajeros románticos: creación y pervivencia del mito andaluz desde una perspectiva geográfica», en Josefina Gómez Mendoza, et al. (eds.), Viajeros y Paisajes, Madrid: Alianza Universidad.

Moulton, Louise Chandler (1896): Lazy Tours in Spain and Elsewhere, Boston: Roberts Brothers.

Ortas Durand, Esther (2005): «La España de los viajeros (1755-1846): Imágenes reales, literaturizadas, sońadas...», en Leonardo Romero Tobar y Patricia Almarcegui (eds.), Los libros de viaje: realidad vivida y género literario, Madrid: Akal-Universidad Internacional de Andalucía, 48-91.

Pillet Capdepón, Félix (2006): «La imagen literaria de La Mancha desde la publicación del Quijote», en Félix Pillet Capdepón y Julio Plaza Tabasco (coords.), El espacio geográfico del Quijote en Castilla-La Mancha, Cuenca: Universidad de Castilla-La Mancha, 35-62.

Roот, Elihu (1922): «A Requisite for the Success of Popular Diplomacy», Foreign Affairs 1: 3-10.

Schriber, Mary Suzanne (ed.) (1995): Telling Travels: Selected Writings by Nineteenth-Century American Women Abroad, DeKalb: Northern Illinois University Press.

Smith, Sidonie (2001): Moving Lives: Twentieth-Century Women's Travel Writing, Minneapolis: University of Minnesota Press.

Stowe, William W. (1991): "Conventions and Voices in Margaret Fuller’s Travel Writing», American Literature 63 (2): 243.

STowe, William W. (1994): Going Abroad: European Travel in Nineteenth-Century American Culture, Princeton, NJ: Princeton University Press.

Yzerbyt, Vincent \& Georges Schadron (1996): Connaître et juger autrui: Une introduction à la cognition sociale, Grenoble: Presses Universitaires de Grenoble.

Zabalgoitia Herrera, Mauricio (2015): «Viajeras de la fantasía I. Estadounidenses por España en el fin de siècle», Informes USA, 34 (febrero), Alcalá de Henares: Instituto Franklin-UAH. 
